\title{
Doação de órgãos em serviço hospitalar: principais motivos à negativa na autorização
}

Organ donation in hospital servises: the principal reasons for authorization refusals Donación de órganos en el servicio hospitalario: principals razones para denegar la autorización

\section{Karen Gabriela Bucelli Pereira ${ }^{\mathrm{I}}$, Verusca Soares de Souza ${ }^{\mathrm{II}}$, Dandara Novakowski Spigolon ${ }^{\mathrm{III}}$ Elen Ferraz Teston ${ }^{\mathrm{IV}}$, João Lucas Campos de Oliveirav ${ }^{\mathrm{v}}$, Felipe Gutierre Moreira ${ }^{\mathrm{VI}}$}

\begin{abstract}
Resumo: Objetivo: analisar os fatores limitadores à doação de órgãos e tecidos para transplantes de um serviço hospitalar. Método: estudo documental, realizado em um hospital do Paraná, Brasil. Analisou-se os "Relatórios de Óbitos e Monitoramento de Doações Mensais”, compreendidos no período de janeiro a dezembro de 2016, registrados pela Comissão Intra-Hospitalar de Doação de Órgãos e Tecidos para Transplantes, por meio de estatística descritiva. Resultados: prevaleceram óbitos por parada cardiorrespiratória, tendo o doador contrário a doação em vida como motivo de não autorização. Dos 54 potenciais doadores, foi autorizada a doação de 27 (50\%) indivíduos, que resultou na doação de 68 órgãos/tecidos, com destaque para córneas. Conclusão: a falta de conscientização da população que gerou a negativa na autorização da doação e o fato de que óbitos por parada cardiorrespiratória dificultaram a captação de múltiplos órgãos frente a isquemia imediata, constituíram os principais limitadores à doação de órgãos no serviço investigado.
\end{abstract}

Descritores: Doadores de tecidos; Obtenção de tecidos e órgãos; Estrutura dos serviços; Enfermagem

Abstract: Objective: To analyze the limiting factors for organ and tissue donation for transplantation in a hospital service. Method: documentary study, performed in a hospital in Paraná, Brazil. The "Reports of Deaths and Monthly Donation Monitoring", from January to December 2016, recorded by the Intra-Hospital Committee on

\footnotetext{
${ }^{\text {I }}$ Enfermeira. Graduada pela Universidade Estadual do Paraná, Paranavaí, Paraná, Brasil. E-mail: karen_bucelli@hotmail.com; ORCID: https://orcid.org/0000-0002-6834-8797

II Enfermeira. Doutora em Enfermagem. Docente da Universidade Federal do Mato Grosso do Sul, Coxim, Mato Grosso do Sul, Brasil. E-mail: verusca.souza@ufms.br; ORCID: https://orcid.org/0000-0003-3305-6812

III Enfermeira. Doutora em Ciências da Saúde. Docente da Universidade Estadual do Paraná, Paranavaí, Paraná, Brasil. E-mail: dandaraspigolon@gmail.com; ORCID: https://orcid.org/0000-0002-9615-4420

${ }^{\text {IV }}$ Enfermeira. Doutora em Enfermagem. Docente da Universidade Federal do Mato Grosso do Sul, Campo Grande, Mato Grosso do Sul, Brasil. E-mail: elen-1208@hotmail.com; ORCID: https://orcid.org/0000-0001-6835-0574

${ }^{\vee}$ Enfermeiro. Doutor em Enfermagem. Docente da Universidade Federal do Rio Grande do Sul, Porto Alegre, Rio Grande do Sul, Brasil. E-mail: joao-lucascampos@hotmail.com; ORCID: https://orcid.org/0000-0002-1822-2360

VI Enfermeiro. Graduado pela Universidade Estadual do Paraná, Paranavaí, Paraná, Brasil. E-mail: flpgutierre@gmail.com; ORCID: https://orcid.org/0000-0002-3984-8629
} 
Doação de órgãos em serviço hospitalar: principais motivos à negativa na autorização | 2

Donation of Transplant Organs and Tissues, were analyzed using descriptive statistics. Results: deaths due to cardiopulmonary arrest prevailed, with the donor opposing the donation in life as a reason for non-authorization. Of the 54 potential donors, $27(50 \%)$ individuals were authorized to donate, resulting in 68 organs / tissues, especially corneas. Conclusion: the lack of awareness of the population that led to the negative authorization of the donation and the fact that deaths from cardiopulmonary arrest made it difficult to capture multiple organs in the face of immediate ischemia were the main limitation of organ donation in the investigated service.

Descreptors: Tissue donors; Tissue and organ procurement; Structure of services; Nursing

Resumen: Objetivo: analizar los factores que limitan la donación de órganos y tejidos para trasplante. Método: estudio documental, realizado en un hospital de Paraná, Brasil. Los "Informes de defunciones y monitoreo mensual de donaciones", de enero a diciembre de 2016, registrados por el Comité intrahospitalario de donación de órganos y tejidos de trasplantes, se analizaron mediante estadísticas descriptivas. Resultados: prevalecieron las muertes por paro cardiopulmonar, y el donante se opuso a la donación en la vida como motivo de no autorización. De los 54 posibles donantes, 27 (50\%) individuos fueron autorizados a donar, lo que resultó en 68 órganos/tejidos, especialmente córneas. Conclusión: la falta de conciencia de la población que condujo a la autorización negativa de la donación y el hecho de que las muertes por paro cardiopulmonar dificultaron la captura de múltiples órganos ante la isquemia inmediata fueron la principal limitación de la donación de órganos en el servicio investigado.

Descreptores: Donantes de tejidos; Obtención de tejidos y órganos; Estructura de los servicios; Enfermería

\section{Introdução}

Os avanços científicos, tecnológicos, organizacionais e sociais têm colaborado para o crescente número de transplantes de órgãos no Brasil e no mundo, ainda que insuficientes diante da vasta quantidade de pessoas que aguardam nas filas de espera. Tal realidade é impactante pois, em muitos casos, a disposição de órgãos, tecidos e células do corpo humano para fins de transplante e tratamento, é a única alternativa terapêutica para os pacientes que apresentam insuficiência terminal de diferentes órgãos. ${ }^{1}$

No Brasil, em 2017, a taxa de doadores efetivos cresceu 14\%, atingindo 16,6 por milhão da população (pmp), sendo representada pelo aumento de $3,8 \%$ na taxa de notificação de potenciais doadores $(51,6 \mathrm{pmp})$ e de $10,2 \%$ na taxa de efetivação de doadores $(32,4 \%){ }^{2}$ Entretanto, ao analisar a taxa de potenciais doadores verifica-se uma significativa desigualdade entre a demanda de órgãos para transplante e o número de transplantes efetivados. Isso porque são elevados os índices de recusa familiar à doação e alguns programas apresentam limitações 
3 | Pereira KGB, Souza VS, Spigolon DN, Teston EF, Oliveira JLC, Moreira FG

financeiras. O índice de notificações de morte encefálica ainda é baixo e a disparidade entre os Estados quanto ao número de doações efetivas, é notória. ${ }^{2-4}$

Vale salientar que o potencial doador é o indivíduo que sofreu Morte Encefálica (ME), que pode promover a doação de múltiplos órgãos, ou aquele que evoluiu ao óbito por Parada Cardiorrespiratória (PCR) podendo doar apenas tecidos que possuem maior tempo de isquemia, tal como globo ocular. ${ }^{5}$ De acordo com o Conselho Federal de Medicina (CFM), o protocolo atualizado em 2017 definiu ME como parada total ou irreversível das funções encefálicas, sendo que os procedimentos para sua determinação se iniciam quando o indivíduo está em coma não perceptivo, ausência de reatividade supraespinhal, apneia persistente e lesão encefálica de causa conhecida e irreversível. ${ }^{6}$

O protocolo ainda exige os exames clínicos e complementares que confirmem estado de ME, a fim de evitar seu diagnóstico equivocado. Ademais, aponta uma redução no intervalo dos testes de reflexo para comprovação do óbito, com uma hora entre a primeira e segunda bateria de testes clínicos, associado a exames de imagem, que podem ser a angiografia cerebral, eletroencefalograma, doppler transcraniano ou cintilografia cerebral. ${ }^{6}$

A carência de informações sobre a ME repercute em dificuldades de entendimento social sobre a realidade e um dos motivos se deve ao fato de que os monitores cardíacos podem demonstrar traçado elétrico compatível com a "vida", mesmo na constatação de ME. $^{7}$ Nesse sentido, a maior dificuldade da aprovação dos familiares para doação de órgãos está vinculada à necessidade de imediata abordagem para informar sobre essa possibilidade no momento em que os indivíduos estão passando pelo processo de aceitação da perda, ${ }^{7}$ o que remonta a importância de sensibilização da população para que saibam acerca do interesse ou não de seus familiares em ser doador.

Apesar de ser um direito reconhecido ao familiar anuir ou não ao processo de doação de órgãos, é inegável que esse meio terapêutico tem melhorado a sobrevida e a qualidade de vida de 
Doação de órgãos em serviço hospitalar: principais motivos à negativa na autorização | 4

muitas pessoas, o que remete à necessidade de os profissionais e serviços de saúde estarem devidamente preparados para aumentar seus índices de captação e transplante de órgãos e tecidos. ${ }^{5}$ Dessa forma, conhecer os aspectos que limitam a atuação do profissional e como consequência, a doação de órgãos, pode subsidiar o replanejamento das ações.

Frente ao contexto explanado, postula-se que estudos que investiguem as características de potenciais doadores, o perfil de doação de órgãos e motivos que levaram ao não consentimento desta ação por meio da análise dos formulários dos serviços, podem auxiliar na detecção de eventuais vulnerabilidades que possam interferir na efetiva doação, provendo subsídios para o planejamento de ações que melhorem a eficácia do processo. Desta forma, questiona-se quais são os fatores limitadores à doação de órgãos e tecidos para transplantes de um serviço hospitalar. E, para respondê-la, objetivou-se analisar os fatores limitadores à doação de órgãos e tecidos para transplantes de um serviço hospitalar.

\section{Método}

Trata-se de um estudo transversal, descritivo, retrospectivo, de fonte documental. Foi realizado em uma instituição hospitalar filantrópica, sem fins lucrativos, localizada em um município no interior do Estado do Paraná, Brasil, e que é credenciada pelo Sistema Nacional de Transplante. O serviço responsável às ações de doação de órgãos funciona desde 2014.

O recorte temporal de estudo compreendeu o período de janeiro a dezembro de 2016. Deste período, foram analisados todos os "Relatórios de Óbitos e Monitoramento de Doações Mensais”, que são documentos registrados pela Comissão Intra-Hospitalar de Doação de Órgãos e Tecidos para Transplantes (CIHDOTT) do hospital.

A coleta de dados ocorreu no período entre julho e agosto de 2018, por meio de um formulário elaborado pelas pesquisadoras, destinado à extração manual de variáveis relacionadas à caracterização demográfica do potencial doador/doador (idade e sexo), 
caracterização demográfica e clínica do doador (idade, sexo, diagnóstico médico e motivo do óbito) e procedimentos relacionados à doação (abordagem da família, perdas, autorização e motivos para não autorização), conforme o que é preconizado na legislação vigente.

Após a coleta, os dados foram tabulados em planilha eletrônica e submetidos à análise estatística descritiva, com uso de medidas de proporção em percentual, tendência central (média) e amplitude (mínimo e máximo).

Todos os preceitos éticos em pesquisas que envolvem seres humanos foram respeitados. A proposta desta pesquisa foi aprovada no Comitê de Ética em Pesquisa envolvendo seres humanos sob o parecer número 2.566.663 de 27 de março de 2018.

\section{Resultados}

Dos 614 óbitos que ocorreram em 2016 na instituição, prevaleceram 343 do sexo masculino (55,9\%), com idade média de 62 anos. Do total, 602 foram óbitos provenientes de Parada Cardiorrespiratória (98\%) e 12 por ME (2\%).

Dentre os óbitos investigados, a maior parte (91,2\%) não cumpria os critérios necessários à caracterização enquanto potencial doador de órgãos. A Tabela 1 apresenta os principais motivos de exclusão de óbitos, segundo critérios da legislação.

Tabela 1 - Exclusões de óbitos como potenciais doadores, segundo critérios da legislação (n=560). Município do Paraná, 2016.

\begin{tabular}{|c|c|c|}
\hline Motivos & $\mathbf{n}$ & $\%$ \\
\hline Fora da faixa etária ( $\geq 75$ anos) & 363 & 64,8 \\
\hline Órgão ou tecido inviável para captação (cicatriz corneana/globo ictérico) & 44 & 7,9 \\
\hline Sepse & 22 & 3,9 \\
\hline Infecção grave (bacteriana/viral em atividade) & 91 & 16,3 \\
\hline Neoplasias & 08 & 1,4 \\
\hline Diagnóstico desconhecido & 10 & 1,8 \\
\hline Hemodiluição & 5 & 0,9 \\
\hline Sorologia positiva & 11 & 2 \\
\hline Outras contraindicações clínicas* & 6 & 1 \\
\hline
\end{tabular}


Doação de órgãos em serviço hospitalar: principais motivos à negativa na autorização |6

Legenda: n: número total; \%: percentual. Fonte: Comissão Intra-Hospitalar de Doação de Órgãos e Tecidos para Transplantes CIHDOTT.

${ }^{*}$ Maquiagem definitiva/Tatuagens; Histórico de tuberculose/Incerteza do tratamento.

Foram abertos 54 protocolos de potenciais doadores de órgãos e tecidos, apresentados quanto a características demográficas e clínicas na Tabela 2.

Tabela 2 - Caracterização demográfica e clínica dos potenciais doadores de órgãos e tecidos ( $\mathrm{n}=54$ ). Município do Paraná, 2016.

\begin{tabular}{|c|c|c|c|}
\hline & Variável & $\mathbf{n}$ & $\%$ \\
\hline \multirow[t]{2}{*}{ Sexo } & Masculino & 37 & 68,5 \\
\hline & Feminino & 17 & 31,5 \\
\hline \multirow[t]{8}{*}{ Idade } & 61 a 70 & 15 & 27,8 \\
\hline & 51 a 60 & 12 & 22,2 \\
\hline & 21 a 30 & 8 & 14,8 \\
\hline & 41 a 50 & 6 & 11 \\
\hline & 31 a 40 & 5 & 9,3 \\
\hline & 11 a 20 & 3 & 5,6 \\
\hline & 03 a 10 & 3 & 5,6 \\
\hline & 71 a 75 & 2 & 3,7 \\
\hline \multirow[t]{2}{*}{ Óbito } & Parada cardiorrespiratória & 44 & 81,5 \\
\hline & Morte encefálica & 10 & 18,5 \\
\hline \multirow[t]{18}{*}{ Diagnóstico Médico } & Acidente vascular cerebral & 10 & 18,5 \\
\hline & Choque cardiogênico & 8 & 14,8 \\
\hline & Infarto agudo do miocárdio & 7 & 13,0 \\
\hline & Insuficiência respiratória aguda & 5 & 9,3 \\
\hline & Politrauma & 5 & 9,3 \\
\hline & Ferimento por arma de fogo & 4 & 7,4 \\
\hline & Edema agudo de pulmão & 2 & 3,7 \\
\hline & Traumatismo cranioencefálico & 2 & 3,7 \\
\hline & Intoxicação exógena & 1 & 1,9 \\
\hline & Cardiopatia (arritmia) & 1 & 1,9 \\
\hline & Pancreatite & 1 & 1,9 \\
\hline & Disfunção de múltiplos órgãos & 1 & 1,9 \\
\hline & Doença pulmonar obstrutiva crônica & 1 & 1,9 \\
\hline & Insuficiência renal aguda & 1 & 1,9 \\
\hline & Hemorragia digestiva alta & 1 & 1,9 \\
\hline & Tromboembolismo pulmonar & 1 & 1,9 \\
\hline & Hérnia cerebral & 1 & 1,9 \\
\hline & Engasgo por corpo estranho & 1 & 1,9 \\
\hline
\end{tabular}

Legenda: n: número total; \%: percentual. Fonte: Comissão Intra-Hospitalar de Doação de Órgãos e Tecidos para Transplantes CIHDOTT. 
Dentre os 54 potenciais doadores, ocorreram oito perdas relacionadas a situações logísticas, a saber: seis por não localização ou comparecimento de familiares em tempo hábil do órgão para realizar doação (11\%) e dois por terem ocorrido no período noturno e o enfermeiro do plantão não ter comunicado a CIHDOTT do óbito (3,7\%). Após tais perdas, ocorreram 46 entrevistas junto à familiares que resultaram em 19 (35,4\%) perdas por não autorização de doação dos familiares, conforme descritas na Tabela 3.

Tabela 3 - Distribuição de motivos de não autorização a doação de órgãos por familiares em uma instituição hospitalar (n=19). Município do Paraná, 2016.

\begin{tabular}{lcc}
\hline \multicolumn{1}{c}{ Motivos da não autorização } & n & \% \\
\hline Doador contrário a doação em vida & 7 & 13,0 \\
Desacordo entre familiares & 3 & 5,6 \\
Desconhecimento do desejo do potencial doador & 3 & 5,6 \\
Desejo familiar do corpo íntegro & 3 & 5,6 \\
Recusa familiar/não justificou motivo & 3 & 5,6 \\
\hline
\end{tabular}

Legenda: n: número total; \%: percentual. Fonte: Comissão Intra-Hospitalar de Doação de Órgãos e Tecidos para Transplantes - CIHDOTT.

Aplicando-se todos os critérios e etapas do processo de doação, foi autorizada a doação de órgãos de 27 indivíduos (50\%), que resultou na doação de 68 órgãos/tecidos para transplantes, especificados na Tabela 4.

Tabela 4 - Distribuição de doações de órgãos efetivadas (n=68), por órgão. Município do Paraná, 2016.

\begin{tabular}{|c|c|c|}
\hline Órgãos doados & $\mathbf{n}$ & $\%$ \\
\hline Córneas & 25 & 46,3 \\
\hline Globo ocular & 19 & 35,2 \\
\hline Valvas cardíacas & 3 & 5,6 \\
\hline Rim & 12 & 22,2 \\
\hline Fígado & 4 & 7,4 \\
\hline Pâncreas & 3 & 5,6 \\
\hline Coração & 1 & 1,9 \\
\hline Ossos & 1 & 1,9 \\
\hline
\end{tabular}

Legenda: n: número total; \%: percentual. Fonte: Comissão Intra-Hospitalar de Doação de Órgãos e Tecidos para Transplantes - CIHDOTT. 
Doação de órgãos em serviço hospitalar: principais motivos à negativa na autorização | 8

\section{Discussão}

A maior parte de indivíduos do sexo masculino pode estar associada ao fato da menor busca deste público pelos serviços de saúde, mesmo com uma maior vulnerabilidade para doenças crônicas. ${ }^{8}$ Pela baixa procura de serviços de promoção à saúde e prevenção de doenças, a porta de entrada dos indivíduos do sexo masculino, por vezes, se caracteriza por serviços de média ou alta complexidade, o que gera um maior risco aos casos.

A maior causa de exclusão de potenciais doadores de órgãos esteve relacionada a faixa etária superior a 70 anos de idade. Embora na instituição investigada para ser um potencial doador o indivíduo deve ter menos de 70 anos, ainda sim, algumas literaturas asseguram que o determinante para doação está relacionado ao estado geral de saúde do concessor. ${ }^{9}$ Dessa forma, sugere-se a reflexão se o grande número de perdas não poderia ser diminuído se a avaliação fosse baseada, exclusivamente, nos critérios clínicos.

O predomínio de potenciais doadores foi de homens, com idade variável de 51 a 70 anos que tiveram como principal causa de óbito a parada cardiorrespiratória. No Brasil, a mortalidade na população masculina está associada, em primeiro lugar, as causas externas, seguidas de doenças do aparelho circulatório e neoplasias. ${ }^{10}$ Neste estudo, a caracterização dos potenciais doadores de órgãos e tecidos cederam lugar ao diagnóstico médico de acidente vascular cerebral (AVC), seguido de choque cardiogênico, dado também encontrado em outra investigação em que 53,9\% dos potenciais doadores tiveram como causa de ME o AVC.11-12

Os dados identificados corroboram com a principal causa de mortalidade no mundo por doenças cardiovasculares, o que representa cerca de $30 \%$ dos óbitos no Brasil. Em geral, as doenças cardiovasculares podem ser prevenidas por meio da abordagem de fatores de riscos comportamentais como o tabagismo, alimentação inadequada, alcoolismo, hipertensão arterial e diabetes mellitus. ${ }^{13}$ Nesse cenário percebe-se a importância da prevenção e investimentos em educação para saúde, em especial, do homem. Para tanto, as estratégias estabelecidas pela 
9 | Pereira KGB, Souza VS, Spigolon DN, Teston EF, Oliveira JLC, Moreira FG

Política Nacional de Saúde do Homem devem ser fortalecidas, discutidas e efetivamente implementadas pelos profissionais de saúde na prática diária do serviço. ${ }^{14}$

Outro ponto que se cumpre destacar, são os motivos de não autorização de doação por familiares. Isso porque, apesar de todos os esforços da equipe multiprofissional, ainda há outros critérios que acabam eliminando potenciais doadores como, por exemplo, o doador ser contrário a doação em vida. Muitas vezes, a ausência de informações adequadas disponibilizadas pode gerar desconforto e descontentamento por parte dos familiares, contribuindo negativamente para o consentimento da doação. ${ }^{15}$

Uma das grandes indagações entre os familiares perpassa o entendimento do significado da ME. Tal falto é evidenciado pela manutenção do funcionamento cardíaco e demais órgãos, mesmo que de modo artificial, ${ }^{16}$ o que pode causar hesitação nas famílias em aceitar o fim da vida, problema esse, passível de resolução por meio de educação em saúde junto à população e, principalmente, dos profissionais de saúde. A falta de informações adequadas pode gerar interpretações errôneas, o que torna necessário o desenvolvimento de ações e campanhas de conscientização da população frente aos critérios para doação de órgãos, de modo que não se restrinja a ações pontuais, mas sim que integrem a rotina de trabalho dos diferentes pontos de atenção à saúde.

Outro fator determinante à recusa familiar está relacionado ao desejo pelo corpo integro. É frequente o receio em autorizar a doação por acreditar-se que na manipulação do corpo do ente pode acontecer deformidades na retirada dos órgãos, consequentemente dificultando na liberação do corpo para o velório. Neste contexto, destaca-se a religião enquanto fator influenciador na decisão familiar, identificado em um estudo, ${ }^{15}$ que enfatizou a questão religiosa como um dos principais motivos da recusa familiar.

Outras perdas por questões logísticas, demonstram o despreparo da equipe e a educação permanente insuficiente acerca do processo. Assim, o investimento na educação permanente de 
Doação de órgãos em serviço hospitalar: principais motivos à negativa na autorização | 10

todos os envolvidos no processo de doação é necessário para melhoria das condições de trabalho dos profissionais envolvidos junto a parceria com redes de apoio. ${ }^{17}$

Mesmo diante desses percalços, o número de doações efetivadas se apresentou em $50 \%$ do total de famílias abordadas. O maior número de órgãos doados ainda é o globo ocular e as córneas, devido aos indivíduos em diagnóstico PCR quando comparado aos de ME. O crescente aumento de doações colocou o Paraná em destaque nacional no ano de 2016 pela taxa semelhante à dos países com melhor desempenho no mundo. ${ }^{2}$ Esse destaque pode estar relacionado as políticas do Sistema Estadual de Transplante do Paraná (SET-PR), que investe e estimula a atualização de profissionais atuantes no processo de doação, considerando esse aspecto incentivador para que haja melhora no desempenho de doações. ${ }^{18}$

No tocante ao número de doações, a efetivação de 50\% dos potenciais doadores aproxima o índice de 48,7\% do Estado do Paraná de acordo com o SET-PR, entre os anos de 2011-2016, ${ }^{16} \mathrm{e}$ fica distante do estudo realizado na cidade de Natal-RN em seis hospitais identificando efetivação de $27,7 \%{ }^{19} \mathrm{O}$ gradiente entre as duas regiões do país corrobora com os dados da Associação Brasileira de Transplantes de Órgãos que identificou um aumento das efetivações na região Sul em 2016, especialmente no Paraná, com 42\% de crescimento, alcançando a taxa de $30,0 \mathrm{pmp}$, duas vezes maior que a média nacional de $14,6 \mathrm{pmp} .2$

Para otimizar este desempenho, a segurança do paciente também é um aspecto crucial na manutenção do processo de efetivação e doações. Isso porque necessita transitar em todos os cenários da gestão do cuidado, uma vez que a assistência prestada é resultante da integração entre os profissionais da saúde e os serviços de saúde envolvidos. Essa indissociabilidade, quando bem conduzida, evita a ocorrência de erros e/ou eventos adversos no processo de doação e gerência do cuidado. ${ }^{20-21}$

Por fim, articular estratégias enfatizadas na padronização dos processos por meio de Educação Permanente tanto aos profissionais quanto a população, pode potencializar a tomada 
de decisão segura e qualificada $\mathrm{E}$ com isso fortalecer esta prática de cuidado e melhorar os resultados de saúde, por meio da doação e transplante de órgãos e tecidos.

Neste estudo não foi possível a associação das especificidades dos resultados encontrados junto a parte estrutural (física, materiais) e organizacional (fluxograma de atendimento e recursos humanos) como influência nos desfechos e sucesso das doações efetivas, recomendando-se a realização de futuras investigações.

\section{Conclusão}

Conclui-se que o perfil de potenciais doadores se concentra em homens adultos e idosos com óbito advindo de causa de ordem cardiovascular. Os principais motivos à negativa na autorização da doação de órgãos, possivelmente, se vinculam às interferências socioculturais sobre o processo, frente ao desconhecimento da população sobre os aspectos que envolvem a doação de órgãos e a vinculação no imaginário social do rompimento com a integridade corporal.

Outro ponto limitante à doação de órgãos relaciona-se ao perfil clínico dos pacientes investigados, visto que a maior parte dos óbitos na instituição ocorreu por parada cardiorrespiratória, fato que restringe a captação de múltiplos órgãos devido ao tempo de isquemia que permite a viabilidade do tecido.

Não foi possível verificar a associação dos motivos de não autorização em relação às características socioculturais de pacientes e seus familiares, aspecto apontado como de interesse à investigações futuras. Apesar disso, acredita-se que o estudo contribui na área de doação de órgãos, por representar um diagnóstico situacional que favorece a tomada de decisão de profissionais de saúde envolvidos na área, rumo à melhoria dos índices de doação. 
Doação de órgãos em serviço hospitalar: principais motivos à negativa na autorização | 12

\section{Referências}

1. International Transplant Nurses Society (ITNS). Introduction to transplant nursing: core competencies. Pittsburg: International Transplant Nurses Society; 2011.

2. Associação Brasileira de Transplantes de Órgãos. Dimensionamento dos Transplantes no Brasil e em cada estado (2010-2017). Registro Brasileiro de Transplantes [Internet]. 2017 [acesso em 2018 ago 10];23(4). Disponível em: http://www.abto.org.br/abtov03/Upload/file/RBT/2017/rbt-imprensa-leituracompressed.pdf

3. Westphal GA, Caldeira Filho M, Vieira KD, Zaclikevis VR, Bartz MCM. Diretrizes para manutenção de múltiplos órgãos no potencial doador adulto falecido. Parte I: aspectos gerais e suporte hemodinâmico. Rev Bras Ter Intensiva. 2011; 23(3):255-68.

4. Monte AS, Lima LRF, Freire VS. Análise epidemiológica dos candidatos à doação de órgãos nos estados do Ceará, São Paulo e Acre. Rev Pesqui Cuid Fundam [Internet]. 2019 [acesso em 2019 ago 19]; 11(1):167-72. Disponível em: http://ciberindex.com/c/ps/P111167

5. Reginaldo P, Padilha EF, Hofstatter LM, Ansolin AGA, Silva EAA. Elementos clínico-epidemiológicos de entrevistas familiares para doação de órgãos e tecidos. Enferm Glob [Internet]. 2017 [acesso em 2018 nov 06];16(46):120-53. Disponível em: http://scielo.isciii.es/pdf/eg/v16n46/pt_1695-6141-eg-16-46-00120.pdf

6. Brasil. Conselho Federal de Medicina. Resolução n. 2.173, de 23 de novembro de 2017. Define os critérios do diagnóstico de morte encefálica. Diário Oficial da União, Brasília (DF); 2017 dez 15. Seção 1, p. 274-5.

7. Pessoa JLE, Schirmer J, Roza BA. Avaliação das causas de recusa familiar a doação de órgãos e tecidos. Acta Paul Enferm [Internet]. 2013 [acesso em 2018 dez 06];26(4):323-30. Disponível em: http://www.scielo.br/pdf/ape/v26n4/v26n4a05.pdf

8. Levorato CD, Mello LM, Silva AS, Nunes AA. Fatores associados à procura por serviços de saúde numa perspectiva relacional de gênero. Ciênc Saúde Colet [Internet]. 2014 abr [acesso em $2018 \mathrm{dez}$ 06];19(4):1263-74. Disponível em: http://www.scielo.br/pdf/csc/v19n4/1413-8123-csc-19-04-01263.pdf

9. Doe Órgãos e Salve Vidas. Doação de órgãos e tecidos: um ato que ajuda ou pode até salvar a vida de uma pessoa [Internet]. São Paulo; 2018 [acesso em 2018 mar 06]. Disponível em: http://doeorgaossalvevidas.com.br/site/doacao-de-orgaos/

10. Ministério da Saúde (BR), Secretaria de Atenção à Saúde, Departamento de Ações Programáticas Estratégicas. Perfil da morbimortalidade masculina no Brasil [Internet]. Brasília (DF): Ministério da Saúde; 2018 [acesso em 2018 dez 06]. 54 p. Disponível em: http://portalarquivos2.saude.gov.br/images/pdf/2018/fevereiro/19/Perfil-da-morbimortalidade-masculinano-Brasil.pdf 
11. Freire ILS, Vasconcelos QLDAQ, Araújo RQ, Melo GSM, Costa IKF, Torres GV. Perfil de potenciais doadores segundo a efetividade da doação. Rev Enferm UFSM [Internet]. 2013 [acesso em 2019 out 14]; 3(N Esp):709-18. Disponível em: http://dx.doi.org/10.5902/2179769210998

12. Freite ILS, Silva MF, Gomes ATL, Dantas BAS, Torres GV. Caracterização de potenciais doadores e estrutura de unidades hospitalares que desenvolvem o transplante. Ciênc Cuid Saude. 2015;14(3):1281-89.

13. Estado do Rio de Janeiro, Secretaria de Saúde, Sociedade de Cardiologia do Estado do Rio de Janeiro. Manual de Prevenção Cardiovascular [Internet]. Rio de Janeiro: SOCERJ . 2017 [acesso em 2018 dez 06]. 96 p. Disponível em: https://socerj.org.br/wpcontent/uploads//2017/05/Manual_de_Prevencao_Cardiovascular_SOCERJ.pdf

14. Ministério da Saúde (BR), Secretaria de Atenção à Saúde, Departamento de Ações Programáticas Estratégicas. Política nacional de atenção integral à saúde do homem: princípios e diretrizes [Internet]. Brasília (DF): Ministério da Saúde; 2008 [acesso em 2018 dez 06]. 40 p. Disponível em: http://bvsms.saude.gov.br/bvs/publicacoes/politica_nacional_atencao_saude_homem.pdf

15. Gois RSS, Galdino MJQ, Pissinati PSC, Pimentel RRS, Carvalho MDB, Haddad MCFL. Efetividade do processo de doação de órgãos para transplantes. Acta Paul Enferm [Internet]. 2017 dez [acesso em 2018 dez 06];30(6):621-7. Disponível em: http://www.scielo.br/pdf/ape/v30n6/0103-2100-ape-30-06-0621.pdf

16. Estado do Paraná, Secretaria de Estado da Saúde do Paraná, Sistema Estadual de Transplante. Manual para notificação, diagnóstico de morte encefálica e manutenção do potencial doador de órgãos e tecidos. Curitiba: SESA/SGS/CET; 2016. 52 p.

17. Oliveira JCAX, Correa ACP, Silva LA, Mozer IT, Medeiros RMK. Perfil epidemiológico da mortalidade masculina: contribuições para enfermagem. Cogitare Enferm [Internet]. 2017 [acesso em 2018 dez 06];(22)2:e49724. Disponível em: http://dx.doi.org/10.5380/ce.v22i2.49742

18. Hoste P, Ferdinande P, Hoste E, Vanhaecht K, Rogiers X, Eeckloo K, et al. Recommendations for further improvement of the deceased organ donation process in Belgium. Acta Clin Belg [Internet]. 2016 out [acesso em 2018 dez 06];71(5):303-12. Disponível em: https://www.ncbi.nlm.nih.gov/pubmed/27594299 doi: $10.1080 / 17843286.2016 .1216259$

19. Freire ILS, Vasconcelos QLDAQ, Torres GV, Araújo EC, Costa IKF, Melo GSM. Estrutura, processo e resultado da doação de órgãos e tecidos para transplante. Rev Bras Enferm [Internet]. 2015 out [acesso em 2018 dez 06];68(5):837-45. Disponível em: http://www.scielo.br/pdf/reben/v68n5/0034-7167-reben-6805-0837.pdf

20. Magalhães ALP, Lanzoni GMM, Knihs NS, Silva EL, Erdmann AL. Segurança do paciente no processo de doação e transplante de órgãos e tecidos. Cogitare Enferm [Internet]. 2017 [acesso em 2018 dez 06];(22)2:e45621. Disponível em: https://revistas.ufpr.br/cogitare/article/view/45621 
21. Basso LD, Salbego C, Gomes IEM, Ramos TK, Antunes AP, Almeida PP. Dificuldades enfrentadas e condutas evidenciadas na atuação do enfermeiro frente à doação de órgãos: revisão integrativa. Ciênc Cuid Saude [Internet]. 2019 jan-mar [acesso em 2019 ago 19];18(1):e42020. Disponível em: https://www.semanticscholar.org/paper/Dificuldades-enfrentadas-e-condutas-evidenciadas-na-BassoSalbego/78d58c1d0884fa3beb634a7d1c846da721ee6c2b

\section{Autor correspondente}

Nome: Verusca Soares de Souza

E-mail: verusca.souza@ufms.br

Endereço: Universidade Federal do Mato Grosso do Sul - Avenida Márcio Lima Nantes, S/N, Coxim/MS

CEP: 79.400-000

Financiamento: O presente trabalho foi realizado com apoio da Coordenação de Aperfeiçoamento de Pessoal de Nível Superior - Brasil (CAPES) - Código de Financiamento 001.

\section{Contribuições de Autoria}

\section{1 - Karen Gabriela Bucelli Pereira}

Concepção e planejamento do projeto de pesquisa, obtenção, análise e interpretação dos dados e redação científica.

\section{2 - Verusca Soares de Souza}

Concepção e planejamento do projeto de pesquisa, análise e interpretação dos dados, redação e revisão crítica.

\section{3 - Dandara Novakowski Spigolon}

Interpretação dos dados, redação científica e revisão crítica.

\section{4 - Elen Ferraz Teston}

Interpretação dos dados, redação científica e revisão crítica

\section{5 - João Lucas Campos de Oliveira}

Interpretação dos dados, redação científica e revisão crítica

\section{6 - Felipe Gutierre Moreira}

Interpretação dos dados, redação científica e revisão crítica

\section{Como citar este artigo}

Pereira KGB, Souza VS, Spigolon DN, Teston EF, Oliveira JLC, Moreira FG. Doação de órgãos em serviço hospitalar: principais motivos à negativa na autorização. Rev. Enferm. UFSM. 2020 [Acesso em: Anos Mês Dia];vol.10, e4: 1-14. DOI:https://doi.org/10.5902/2179769236087 